\title{
Effects of transarterial chemoembolization on the immunological function of patients with hepatocellular carcinoma
}

\author{
JINGJING GUO $^{1 *}$, SAIXIA WANG ${ }^{2 *}$, YUJING HAN ${ }^{3}$, ZHONGYUAN JIA $^{4}$ and RUNCHAO WANG ${ }^{3}$ \\ ${ }^{1}$ Interventional Department of Liver Diseases; ${ }^{2}$ Integrated Outpatient Department; \\ ${ }^{3}$ Integrated Traditional Chinese Medicine and Western Medicine Department, Qingdao Sixth People's Hospital, \\ Qingdao, Shandong 266000; ${ }^{4}$ Department of General Practice, Jinan Maternity and Child Care Hospital Affiliated to \\ Shandong First Medical University, Jinan Maternity and Child Care Hospital, Jinan, Shandong 250000, P.R. China
}

Received June 23, 2020; Accepted March 25, 2021

DOI: 10.3892/ol.2021.12815

\begin{abstract}
The present study aimed to investigate the effects of transarterial chemoembolization (TACE) on the immune function of patients with hepatocellular carcinoma (HCC). A total of 114 patients with HCC were selected and their peripheral blood was collected before and 1 month after TACE treatment. Flow cytometry and reverse transcription-quantitative PCR were performed to analyze the changes in immune function in patients before and after treatment. Kaplan-Meier curves were plotted for survival analysis. The programmed cell death ligand 1 (PD-L1) and programmed cell death protein 1 (PD1) expression before TACE treatment were significantly higher in patients with poor TACE response compared with those patients with well response. Higher PD-L1 mRNA expression in the peripheral blood mononuclear cells after TACE predicted a superior prognosis. After TACE treatment, the proportion of $\mathrm{CD}^{+} / \mathrm{CD}^{+}$cells were decreased while the expression levels of programmed cell death protein 1 (PD1) were significantly increased. To conclude, TACE could reduce the proportion of $\mathrm{CD}^{+} / \mathrm{CD}^{+}$cells and improve the mRNA expression levels of PD1 in patients with HCC. The expression levels of PD1 and PD-L1 were closely related to the therapeutic effect of TACE and the prognosis of patients with HCC. TACE combined with immunotherapy may have potential clinical value for patients with HCC.
\end{abstract}

Correspondence to: Dr Runchao Wang, Integrated Traditional Chinese Medicine and Western Medicine Department, Qingdao Sixth People's Hospital, 9 Fushun Road, Shibei, Qingdao, Shandong 266000, P.R. China

E-mail: runchao1225@163.com

${ }^{*}$ Contributed equally

Key words: immune function, hepatocellular carcinoma, transarterial chemoembolization, programmed cell death protein 1, programmed cell death 1 ligand 1

\section{Introduction}

Hepatocellular carcinoma (HCC) is a common tumor of the digestive system and the second leading cause of tumor deaths worldwide (1). The pathogenesis of HCC is complex, involving environmental factors, dietary habits and familial inheritance, and infection with hepatitis $\mathrm{B}$ or $\mathrm{C}$ virus remains a major risk factor (2). Chronic hepatitis develops into cirrhosis and eventually leads to HCC. In China, which is one of the highly endemic countries, hepatitis B virus carriers account for $20 \%$ of the total population, with a $7-8 \%$ prevalence rate of hepatitis B $(3,4)$. HCC has no specificity in the early stage and is a rapidly progressive disease (5). Numerous patients are diagnosed in the middle and late stages, with poor therapeutic effects and prognosis (3).

Current clinical applications include hepatectomy, liver transplantation, radiofrequency ablation (RFA), transarterial chemoembolization (TACE), and sorafenib $(6,7)$. TACE includes different combinations of chemotherapeutic and embolization drugs. Injection of an embolization agent can obstruct the artery supplying the tumor, resulting in ischemic necrosis of the tumor tissue (8). Chemoembolization agents include anticancer drugs, such as mitomycin and carboplatin or drug microspheres, iodinated oil emulsions and gelatin sponges (6). TACE treatment has been demonstrated to have a positive effect on survival outcomes (9). TACE is a first-line treatment for mid-term HCC, such as asymptomatic, unresectable nodular lesions, no vascular invasion or extrahepatic diffusion and well-preserved liver function (10).

Lei et al (3) compared the effects of oxaliplatin alone and oxaliplatin combined with endostar on the immune function of patients with primary liver cancer. Their study revealed that oxaliplatin combined with endostar was effective in prolonging patient survival time, improving $\mathrm{T}$ lymphocyte subgroup levels and enhancing patient immunity (3). Ito et al (11) reported that RFA improved the efficacy of adaptive T cell therapy in murine models, and this can be supplemented by immunotherapy to achieve more effective results. However, Löffler et al (12) demonstrated that RFA-induced immune effects are not sufficient against tumors. Therefore, the combination of traditional therapy and immunotherapy is worthy of further study. The aim of the present study was to investigate whether 
TACE therapy was associated with immune function in patients with HCC.

\section{Materials and methods}

Patients. A total of 114 patients (age range, 35-91 years old) with HCC were enrolled in the present study at Qingdao Sixth People's Hospital (Qingdao, China). Date of the first diagnosis of HCC was from April 2013 to February 2020. Date of the last follow-up was April 2020. A total of 50 patients were treated by surgery, 10 by biopsies and the rest had neither surgery nor biopsy. The following inclusion criteria were used for the patients: i) First TACE treatment; ii) conformed to the indications of TACE treatment, with no history of radiotherapy or systemic chemotherapy before TACE treatment; iii) no autoimmune diseases present or no drugs affecting immune function were taken 3 months before treatment. The exclusion criteria used were as follows: i) Patients with metastatic liver cancer; ii) patients with serious heart, brain, lung, kidney and blood system diseases; iii) pregnant and lactating women; iv) patients had communication disorders, such as cases with hepatic encephalopathy or depression; and v) unwilling to participate.

The criteria for diagnosis included clinical manifestations, imageology, $\alpha$-fetoprotein (AFP) levels and pathological examination, which met the diagnostic criteria of the Chinese Society of Clinical Oncology guidelines for the diagnosis and treatment of primary liver cancer (v1; 2018) (13). All patients provided signed informed consent for surgery and were treated with TACE. Clinical data were collected by the hospital system. Fresh peripheral blood was collected and stored in tubes with EDTA anticoagulation for assessment of immune function before intervention and 1 month after treatment. Written informed consent was signed by all patients and healthy donors before participation in the study. The present study was approved by the Ethics Committee of Qingdao Sixth People's Hospital (Qingdao, China).

Liver function assessment criteria. Child-Pugh grading system (14) was used to evaluate patient liver function. A total of five indices (including the hepatic encephalopathy, ascites, total bilirubin, albumin and prothrombin time) of patients were divided into 3 levels, corresponding to $1,2,3$, respectively. Finally, scores were added up and a high score indicated the severity of liver damage. See Table I for details.

TACE procedure and treatment response evaluation. All patients were treated with TACE using the Seldinger technique (15). Ultrasound-guided percutaneous insertion of a retrograde catheter was performed from the femoral artery through the celiac trunk and hepatic artery, and the final location of the catheter was determined by the tumor location. Chemotherapeutic drugs, including fluorouracil, mitomycin and carboplatin were mixed with iodized oil to form a pingyangmycin lipiodol emulsion. The mixture was injected into gelfoam to block blood supply to the tumor as embolic agents. The dose and type of chemotherapeutic drug depended on the patient's age, weight, and liver and kidney function. In addition, patients also underwent concomitant therapy, such as disodium cantharidinate $(0.25 \mathrm{~g}$; once daily; intravenous injection) for antitumor therapy, tiopronin ( $0.2 \mathrm{~g}$; once daily; intravenous injection) for liver protection and supportive treatment, such as hemostasis and rehydration to prevent electrolyte disturbances and prophylactic antibiotics for preventing infection in patients after surgery. According to the Response Evaluation Criteria In Solid Tumors (16), the therapeutic effect was evaluated as follows: Complete remission (CR), where all target lesions had disappeared; partial response (PR), where the sum of the longest diameter of target lesions decreased by $\geq 30 \%$; stable disease (SD), indicating neither PR nor progressive disease (PD); and PD, where the sum of the longest diameters of the target lesions increased by $\geq 20 \%$ or new lesions or metastases appeared. CR and PR were defined as a satisfactory response, while SD and PD were regarded as a poor response. Overall survival was defined as the time interval between patients undergoing TACE and death or the last follow-up.

Diagnosis of liver cirrhosis. The diagnostic criteria for cirrhosis included: i) Pseudolobules were diagnosed through percutaneous liver biopsy; and ii) liver stiffness measurement $\geq 17.5 \mathrm{kPa}$ using FibroScan (transient elastography). Patients with either of the aforementioned criteria were diagnosed with liver cirrhosis.

Isolation of human peripheral blood mononuclear cells (PBMCs). Peripheral blood was collected from 114 patients with HCC who received TACE intervention and 20 healthy donors. The recruitment of healthy blood donors at the Sixth People's Hospital of Qingdao (Qingdao, China) began in February 2014 and ended in October 2017. The age range of the healthy controls was 21-67 years. There were 14 men and 4 women. The inclusion criteria used for the healthy contacts were as follows: i) Body mass index (BMI) between 19-26; $>45 \mathrm{~kg}$ for women, $>50 \mathrm{~kg}$ for men; iii) understood fully the purpose of the study and voluntarily signed the informed consent; and iv) had no history of chronic or serious diseases, such as cardiovascular disease, and were in good general health. The exclusion criteria were as follows: i) Had taken any medication within 3 months; ii) Had any medical condition; PBMCs were separated using the Ficoll-Hypaque density gradient deposition method (17). At room temperature, the blood diluted by PBS was centrifuged at $300 \mathrm{x} \mathrm{g}$ for $20 \mathrm{~min}$. Cells of the mononuclear cell layer were collected and cleaned with PBS at room temperature at $300 \mathrm{x} \mathrm{g}$ for $10 \mathrm{~min}$. The precipitated cells were suspended in the medium for later use. PBMCs were washed for 3 min using PBS at room temperature and further analyzed by flow cytometry or reverse transcription-quantitative PCR (RT-qPCR).

Flow cytometric analysis. Flow cytometry was used to detect $\mathrm{CD}^{+}, \mathrm{CD}^{+}$and $\mathrm{CD} 8^{+}$cells. PBMCs were collected, washed for 3 min using PBS at room temperature and centrifuged at $200 \mathrm{x} \mathrm{g}$ for $5 \mathrm{~min}$ at room temperature and the supernatant was discarded. FITC-anti-CD3 (1:200; cat. no. 561806; BD Biosciences), phycoerythrin-anti-CD4 (1:200; cat. no. 561843; BD Biosciences) and allophycocyanin-Cy7-anti-CD8 (1:200; cat. no. 557760; BD Biosciences) antibodies were added, followed by incubation at $4^{\circ} \mathrm{C}$ for $20 \mathrm{~min}$. PBMCs were washed for 5 min using PBS at room temperature. Following centrifugation at $200 \mathrm{xg}$ for $5 \mathrm{~min}$ at room temperature, the PBMCs 
Table I. Child-Pugh grading system.

\begin{tabular}{lccc}
\hline & \multicolumn{3}{c}{ Score } \\
\cline { 2 - 4 } Indices & 1 & 2 & 3 \\
\hline Total bilirubin $(\mu \mathrm{mol} / \mathrm{l})$ & $<34.2$ & $34.2-51.3$ & $>51.3$ \\
Albumin $(\mathrm{g} / \mathrm{l})$ & $\geq 35$ & $28-35$ & $<28$ \\
Prothrombin time $(\mathrm{sec})$ & $1-4$ & $4-6$ & $>6$ \\
Hepatic encephalopathy (grade) & None & 1 or 2 & 3 or 4 \\
Ascites & None & Mild & Moderate \\
\hline
\end{tabular}

It was graded as 5-6 points for Child-Pugh-A; 7-9 points for Child-Pugh-B; and 10-15 points for Child-Pugh-C.

Table II. Primer sequences.

\begin{tabular}{llc}
\hline Gene & Forward primer $\left(5^{\prime}-3^{\prime}\right)$ & Reverse primer $\left(5^{\prime}-3^{\prime}\right)$ \\
\hline PD-L1 & GAGGGAATGCGTATTTTGGGT & AGGTTGTTCTTGTGTCACCTG \\
PD1 & TCGTCCACTGCGGCTTTTTA & GCAAGGTCGGGTATTTAAGCA \\
GAPDH & TGTGGGCATCAATGGATTTGG & ACACCATGTATTCCGGGTCAAT
\end{tabular}

PD1, programmed cell death protein 1; PD-L1, programmed cell death 1 ligand 1.

were resuspended with PBS containing $1 \%$ paraformaldehyde for fixation at room temperature, detected (FACSCanto II; BD Biosciences) and analyzed by CellQuest software v.5.1 (BD Biosciences).

$R N A$ extraction and $R T-q P C R$. Total RNA was extracted from isolated cells using TRIzol ${ }^{\circledR}$ reagent (Thermo Fisher Scientific Inc.) according to the manufacturer's protocol. Extracted total RNA was then reverse transcribed into cDNA. The reaction tube containing total RNA was first held at $37^{\circ} \mathrm{C}$ for $15 \mathrm{~min}$ for reverse transcription, then heated at $85^{\circ} \mathrm{C}$ for $5 \mathrm{~min}$ for inactivation of reverse transcriptase, and cooled to $4^{\circ} \mathrm{C}$ for storage. cDNA was analyzed by qPCR according to the Takara two-step method (Takara Bio, Inc.). The thermocycling conditions were as follows: Firstly, 1 cycle at $95^{\circ} \mathrm{C}$ for $30 \mathrm{sec}$ for initial denaturation; followed by 40 cycles at $95^{\circ} \mathrm{C}$ for $5 \mathrm{sec}$ for denaturation and at last $60^{\circ} \mathrm{C}$ for $30-34 \mathrm{sec}$ for annealing. The primer sequences of programmed cell death 1 ligand (PD-L1) and programmed cell death protein 1 (PD1) are shown in Table II.

The $2^{-\Delta \Delta \mathrm{Cq}}$ method (18) was used to quantify gene expression. GAPDH was used as the internal reference gene.

Statistical analysis. All experiments were performed three times. Quantitative data are presented as the mean \pm standard deviation, and categorical data is shown as the number of cases. Comparisons between before and after treatment were performed using a paired t-test. The association between the levels of PD1/PD-L1 and the efficacy of TACE was assessed using one-way ANOVA followed by Tukey's multiple comparisons test. The association between PD1/PD-L1 expression and survival time was analyzed by Kaplan-Meier analysis with a log-rank test. All data were analyzed using SPSS v22.0
(IBM Corp.) and GraphPad Prism 8.0 software (GraphPad Software, Inc.). $\mathrm{P}<0.05$ was considered to indicate a statistically significant difference.

\section{Results}

Clinicopathological characteristics of patients with HCC. A total of 114 patients with HCC, including 84 male and 30 female patients, were included in the present study (Table III). The mean age was $66.5 \pm 12.6$ years. There were 54 patients who were $>65$ years old and the remaining 60 patients were $\leq 65$ years old. A total of 97 patients had hepatitis B, while 17 patients had hepatitis C. According to the Child-Pugh grading system (14), 89 cases were classified as grade A, 20 cases were classified as grade $\mathrm{B}$ and 5 cases were classified as grade $\mathrm{C}$.

A total of 100 cases were diagnosed with liver cirrhosis. The maximum tumor diameter was $>5 \mathrm{~cm}$ in 55 cases and $\leq 5 \mathrm{~cm}$ in 59 cases. There were 80 cases presenting with a single tumor and 34 cases presenting with multifocal tumors (Table III). Among patients with multifocal tumors, the maximum diameter of multiple tumors ranged between 0.8 and $7.5 \mathrm{~cm}$, with a median of $3.4 \mathrm{~cm}$. A total of 20 patients had two tumors, 8 patients had three tumors, 3 patients had four tumors, 2 patients had five tumors and 1 patient had more than five tumors (seven tumors). The levels of AFP before TACE treatment were $<200 \mathrm{ng} / \mathrm{ml}$ in 54 cases, while 60 patients exceeded these levels. After TACE treatment, AFP levels in 99 cases were $<200 \mathrm{ng} / \mathrm{ml}$ and 15 cases remained at levels of $\geq 200 \mathrm{ng} / \mathrm{ml}$. A total of 59 patients responded well to TACE, while the remaining 55 patients responded poorly. The end date of the follow-up was April 2020, with a median of 23.5 months (range, 3-82 months). A total of 37 patients died and the overall mortality rate was $32.5 \%$ (Table III). 
Table III. Clinicopathologic characteristics of patients with hepatocellular carcinoma $(n=114)$.

\begin{tabular}{ll}
\hline Characteristics & Value \\
\hline
\end{tabular}

\section{Sex, n \\ Male \\ Female}

Mean age \pm std, years

Age, $n$

$>65$ years

$\leq 65$ years

Etiology, n

Hepatitis B

Hepatitis C

Child-Pugh classification, $n$

A
B
C

Liver cirrhosis, $\mathrm{n}$

Present

Absent

Tumor size, $\mathrm{n}$

$\leq 5 \mathrm{~cm}$

$>5 \mathrm{~cm}$

84

30

$66.5 \pm 12.6$

54

60

97

17

89

20

5

100

14

Tumor number, $\mathrm{n}$

Single

Multiple

80

Median maximum diameter of multiple

tumors, cm (range)

Maximum diameter of multiple

tumors, $\mathrm{n}$

$$
\begin{aligned}
& <2 \mathrm{~cm} \\
& 2-5 \mathrm{~cm} \\
& >5 \mathrm{~cm} \\
& \text { Number of multiple tumors, } \mathrm{n} \\
& 2 \\
& 3 \\
& 4 \\
& 5 \\
& >5 \\
& \text { AFP before TACE treatment, } \mathrm{n}(\mathrm{ng} / \mathrm{ml}) \\
& <200 \\
& \geq 200
\end{aligned}
$$

AFP after TACE treatment, $\mathrm{n}(\mathrm{ng} / \mathrm{ml})$

$<200$

$\geq 200$

TACE response, $\mathrm{n}$

Poor

Well

Median follow-up, months (range)

Overall mortality

AFP, $\alpha$-fetoprotein; TACE, transarterial chemoembolization.
Effects of TACE treatment on the immune function of patients. To further verify the effects of TACE treatment on the immune function of patients, the immune status of patients was examined before and after TACE treatment. The levels of $\mathrm{CD}^{+}, \mathrm{CD}^{+} / \mathrm{CD}^{+}, \mathrm{PD} 1$ and PD-L1 were selected as indices to evaluate immune function (Table IV, Fig. 1). Before patients underwent TACE treatment, the mean values of PD1 and PD-L1 mRNA expression levels were 2.496 and 2.853, respectively. After TACE treatment was performed, the mean values of PD1 and PD-L1 mRNA expression levels were 4.312 and 3.11, respectively. $\mathrm{CD}^{+} / \mathrm{CD}^{+}$significantly decreased after TACE treatment $(\mathrm{P}<0.001)$. Notably, the relative mRNA expression levels of PD1 were significantly upregulated $(\mathrm{P}<0.001)$. The mRNA expression levels of PD-L1 were also increased after TACE treatment; however, this difference was not significant $(\mathrm{P}=0.083)$. In addition, there was no significant difference observed in $\mathrm{CD}^{+}$levels $(\mathrm{P}=0.167)$.

To further clarify the association between the therapeutic effects of TACE and PD1/PD-L1 expression, the mRNA expression levels of PD-L1/PD1 were detected in healthy donors and patients, which were divided into well or poor response to TACE groups (Fig. 2A and B). Compared with healthy subjects, the expression levels of PD-L1/PD1 in patients with $\mathrm{HCC}$ were significantly increased $(\mathrm{P}<0.001)$. The mRNA expression levels of both PD-L1 (Fig. 2A) and PD1 (Fig. 2B) in patients with $\mathrm{HCC}$ with poor TACE response were higher compared with those in patients with satisfactory TACE response (all $\mathrm{P}<0.001$ ). Kaplan-Meier curves were plotted to analyze the survival of patients with high and low expression levels of PD1/PD-L1. According to the average mentioned in Table IV, patients were divided into two groups for further analysis. Before patients underwent TACE treatment, PD1 mRNA levels $>2.5$ and PD-L1 mRNA levels $>3.0$ were regarded as high PD1/PD-L1 expression levels, respectively. After TACE treatment was performed, PD1 mRNA expression $>4.0$ and PD-L1 mRNA expression >3.0 were considered as high PD1/PD-L1 expression levels, respectively. There was no statistical difference in survival prognosis between the high expression $\mathrm{PD} 1(\mathrm{P}=0.761) / \mathrm{PD}-\mathrm{L} 1(\mathrm{P}=0.221)$ group and the low expression group before TACE treatment (Fig. 2C and D). However, after TACE treatment, PD-L1 expression could be used to predict the prognosis of patients with HCC. After TACE treatment, compared with high PD-L1 expression, high PD-L1 expression significantly indicated improved prognosis $(\mathrm{P}=0.017)$, while the expression level of $\mathrm{PD} 1(\mathrm{P}=0.371)$ could not predict the prognosis before and after TACE treatment (Fig. 2E and F).

\section{Discussion}

The immune system serves an important role in tumor progression (19). The interaction between the tumor and immune system can be divided into three stages: Immune elimination, immune balance and immune escape (20). In the early stages of tumorigenesis, natural killer cells recognize and kill cancer cells, and the debris is consumed by macrophages. Dendritic cells exposed to cancer cell antigens secrete inflammatory cytokines and present neoantigens to T cells $(20,21)$. T cells and $\mathrm{B}$ cells are then activated, resulting in the activation of cellular immunity, which results in protection against inflammation 
Table IV. Immune parameters in patients with hepatocellular carcinoma before and after TACE treatment.

\begin{tabular}{|c|c|c|c|c|}
\hline Parameter & Before TACE treatment & After TACE treatment & $\mathrm{t}$ & P-value \\
\hline $\mathrm{CD}^{+} / \mathrm{CD}^{+}($mean \pm std $)$ & $1.818 \pm 0.720$ & $1.462 \pm 0.717$ & 4.141 & $<0.001$ \\
\hline $\mathrm{CD}^{+}($mean $\pm \mathrm{std})(\mu \mathrm{l})$ & $81.632 \pm 6.141$ & $82.658 \pm 5.867$ & -1.392 & 0.167 \\
\hline PD1 relative mRNA level & $2.496 \pm 0.939$ & $4.312 \pm 0.558$ & -17.801 & $<0.001$ \\
\hline PD-L1 relative mRNA level & $2.853 \pm 1.048$ & $3.113 \pm 1.209$ & -1.679 & 0.083 \\
\hline
\end{tabular}

PD1, programmed cell death protein 1; PD-L1, programmed cell death 1 ligand 1; TACE, transarterial chemoembolization.

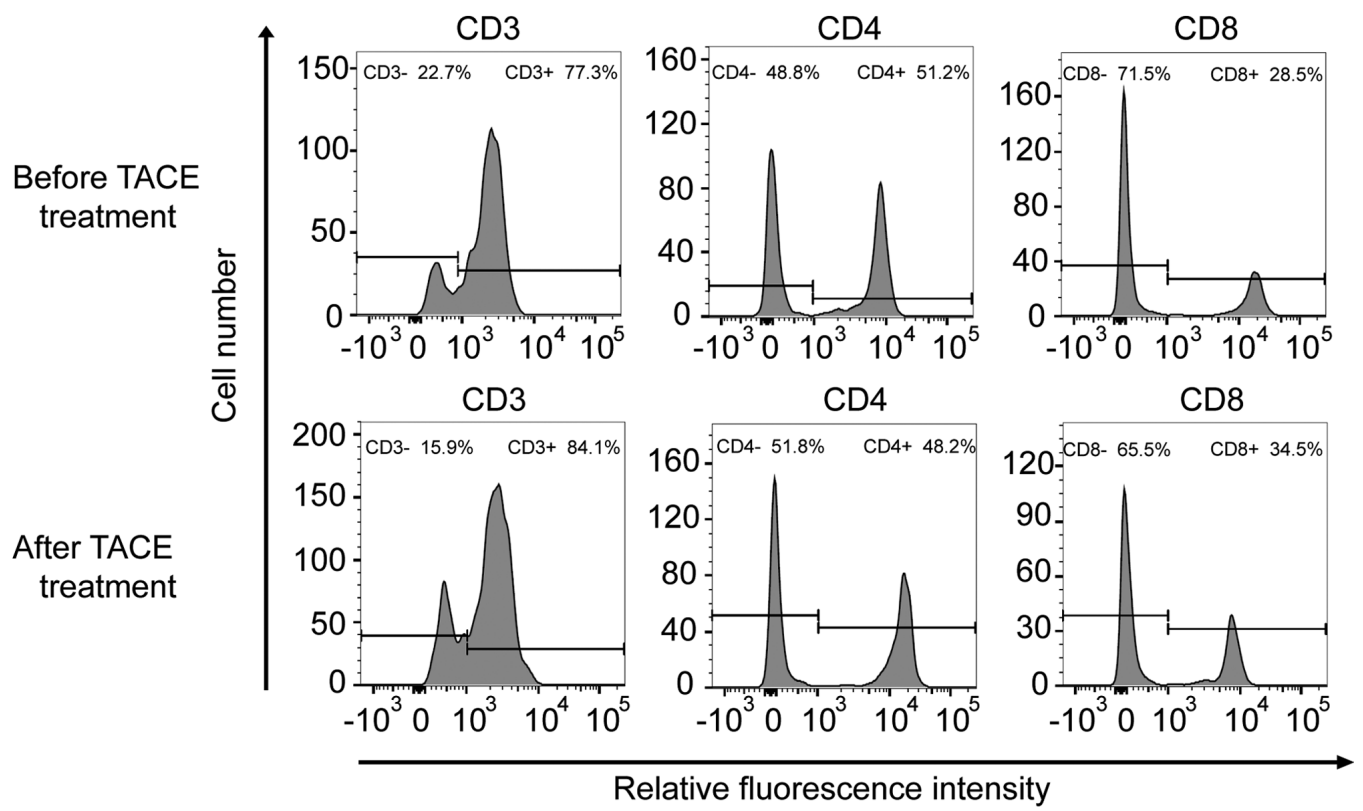

Figure 1. CD3/CD4/CD8 cells representative flow cytometry images before and after TACE treatment. The abscissa is the relative fluorescence intensity and the ordinate is the number of cells. Cell samples were divided into two groups according to fluorescence intensity. The left peak consisted of the CD3/CD4/CD8 cell population, and the right peak consisted of the $\mathrm{CD}^{+} / \mathrm{CD} 4^{+} / \mathrm{CD}^{+}$cell population. TACE, transarterial chemoembolization.

in the body (22). A study by Ge et al (23) on the influence of immune cell infiltration on the prognosis of patients with colon cancer indicated that $\mathrm{CD}^{+} \mathrm{T}$ cell infiltration exerted marked antitumor effects. A high density of $\mathrm{CD}^{+} \mathrm{T}$ cells in advanced gastric cancer has been considered to be associated with favorable prognosis (24). In the present study, PBMCs from 114 patients with HCC were collected to determine the effects of TACE therapy on the immune system. The $\mathrm{CD}^{+} / \mathrm{CD}^{+}$ratio decreased after TACE treatment, indicating that the $\mathrm{CD}^{+}$cells were increased and immune function of the patients was restored (25).

Tumor cells can evade immune surveillance through a variety of mechanisms, including activating immune checkpoints to suppress the antitumor immune response (26). PD1 is expressed on activated T cells, B lymphocytes and natural killer cells. PD1 binds to tumor cells with its cognate ligands (PD-L1), thereby inhibiting T cell proliferation and response, suppressing patient immunity and helping tumor immune escape (27). Studies have revealed that PD1/PD-L1 expression in non-small cell lung cancer, glioblastoma and lymphoma is associated with patient prognosis (28-31). High PD1 expression has been demonstrated to predict improved prognosis in patients with breast cancer (32). A recent study indicated that PD1 has different effects on the prognosis of different subtypes of lymphoma (33). In the present study, the association between PD1/PD-L1 expression and TACE was also analyzed. After TACE treatment, the mRNA expression levels of both PD1 and PD-L1 were increased, and patients with low PD-L1 mRNA expression had a poor prognosis. This result is consistent with that of Hanna et al (34), which showed the high expression of PD-L1 was associated with a good prognosis in young women with oral cavity squamous cell carcinoma. It has been reported that PD-L1 upregulation is associated with antitumor inflammatory response induced by CD8 cell infiltration $(34,35)$. However, the effect of TACE treatment on PD-L1 expression and function of immune cells remains unclear. The association between PD-L1 and prognosis and the intrinsic mechanism require further investigation.

In recent years, immunotherapy has developed rapidly and obtained remarkable achievements. Lee et al (36) revealed that the combination of cytokine-induced killer cell therapy with RFA or TACE could improve patient outcomes. Lee et al (37) reported a positive association between PD-L1 and sorafenib resistance. These results suggested that PD-L1 inhibitors 
A

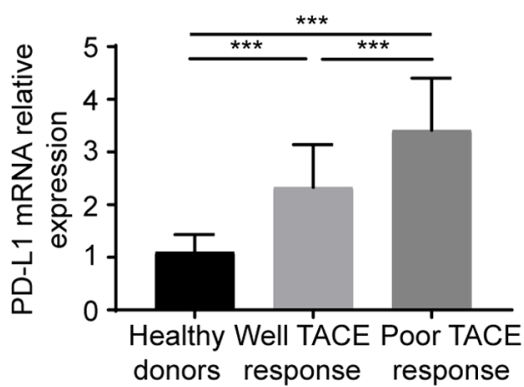

C

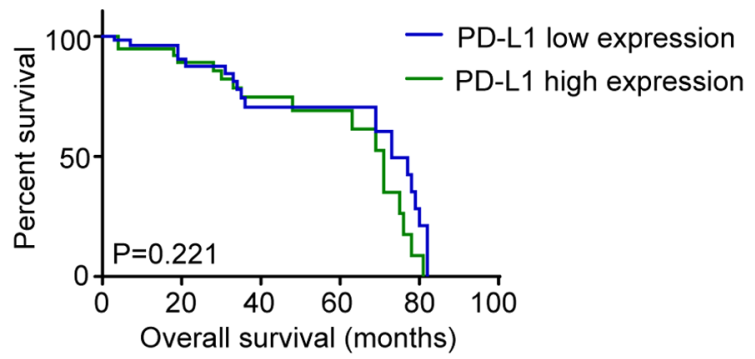

$E$

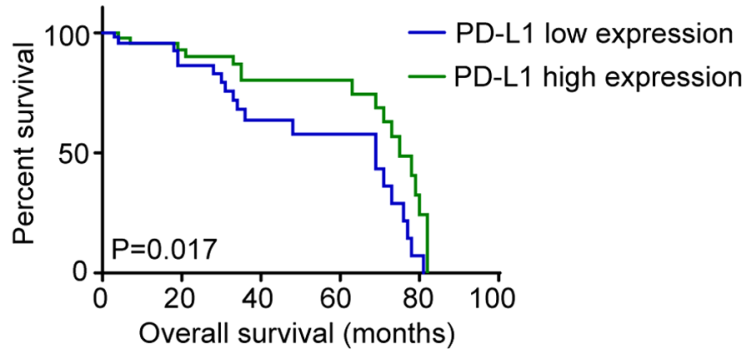

$\mathrm{B}$

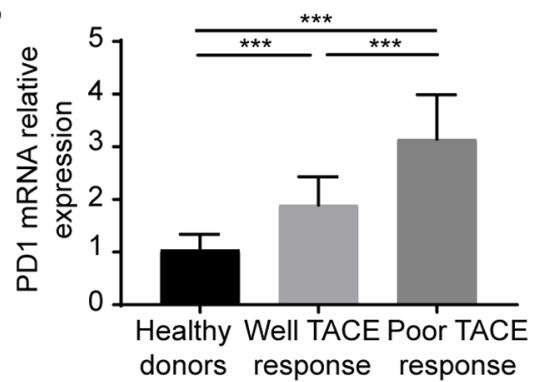

$\mathrm{D}$

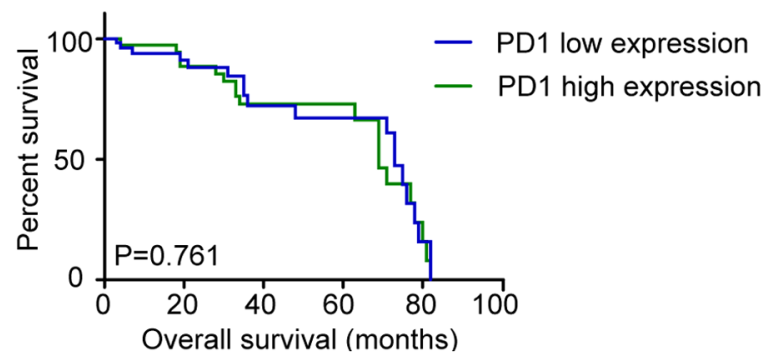

$\mathrm{F}$

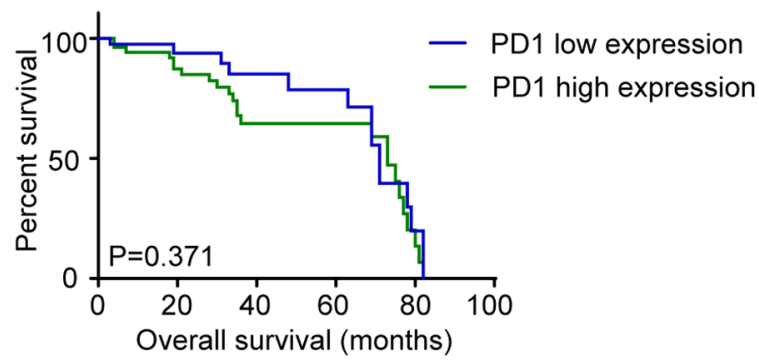

Figure 2. Relationship between PD1/PD-L1 expression and the efficacy and prognosis of TACE (A) mRNA expression levels of PD-L1 in peripheral blood mononuclear cells before TACE treatment. (B) mRNA expression levels of PD1 in peripheral blood mononuclear cells before TACE treatment. (C) Kaplan-Meier analysis of patients with HCC based on PD-L1 mRNA expression before TACE treatment. (D) Kaplan-Meier analysis of patients with HCC based on PD1 mRNA expression before TACE treatment. (E) Kaplan-Meier analysis of patients with HCC based on PD-L1 mRNA expression after TACE treatment. (F) Kaplan-Meier analysis of patients with HCC based on PD1 mRNA expression after TACE treatment. PD1, programmed cell death protein 1; PD-L1, programmed cell death 1 ligand 1 ; HCC, hepatocellular carcinoma; TACE, transarterial chemoembolization. ${ }^{* * *} \mathrm{P}<0.001$.

combined with sorafenib may be a novel strategy to prevent or overcome sorafenib-acquired resistance in patients with HCC (38). In the present study, the expression levels of PD-L1 and PD1 in patients with poor response were higher than those in patients with good response before TACE treatment. In addition, the mRNA expression levels of both PD1 and PD-L1 were increased after TACE treatment. Therefore, further studies are required to determine the therapeutic effects of TACE and immunotherapy combination strategy.

Although the present results indicated that TACE combined with immunotherapy has potential clinical value for patients with HCC, there were also several limitations in the present study. Firstly, the specific mechanism of the increase in PD1 and PD-L1 in PBMCs was not investigated. As for the mechanism of TACE-induced PD1/PD-L1 mRNA upregulation, related studies have reported that, following chemotherapy and targeted drug treatment, residual tumor cells can restore the stemness and enhance immune escape, which is one of the reasons for the failure of existing treatment models (39-41). Furthermore, residual tumor cells have been demonstrated to reshape the surrounding immune microenvironment by upregulating the levels of inhibitory cytokines, such as IL-1 and MMP family proteins, to force suppressive immune cells in the immune microenvironment to complete the immune escape and promote the recurrence of tumor cells $(40,42)$. Due to abundant blood flow in the liver, suppressive cytokines and immune cells may affect the PD1/PD-L1 levels in peripheral blood lymphocytes $(43,44)$. Further studies will be required to evaluate the intrinsic mechanism. Secondly, the present study used RT-qPCR to detect the expression levels of PD1/PD-L1 instead of flow cytometry based on previous studies (45-47), which performed qPCR to detect the expression levels of PD1/PD-L1, it was hypothesized that qPCR is a reliable way for detecting PD1/PD-L1 expression. However, this meant that the present study only detected the mRNA levels of PD1/PD-L1. In addition, more samples should be included in future studies to determine the effect of TACE treatment on immune function.

In summary, the present data demonstrated that TACE could improve the proportion of $\mathrm{CD}^{+}$cells and the mRNA expression level of PD1 in patients with HCC. Before TACE treatment, high PD1 and PD-L1 mRNA levels were significantly associated with poor therapeutic response to TACE. After TACE treatment, high PD-L1 mRNA expression was significantly associated with improved patient prognosis. TACE combined with immunotherapy has potential clinical value for patients with HCC. 


\section{Acknowledgements}

Not applicable.

\section{Funding}

No funding was received.

\section{Availability of data and materials}

All data generated or analyzed during this study are included in this published article.

\section{Authors' contributions}

RW designed the study. YH and ZJ collected and analyzed the data. JG and SW performed the experiments, prepared figures and tables and drafted the manuscript. JG and RW confirmed the authenticity of all the raw data. All authors have read and approved the final manuscript.

\section{Ethics approval and consent to participate}

The present study was approved by the Ethics Committee of Qingdao Sixth People's Hospital (Qingdao, China; approval no. 2013-R-0012). Written informed consent was provided by patients or their guardians prior to the study start.

\section{Patient consent for publication}

Not applicable.

\section{Competing interests}

The authors declare that they have no competing interests.

\section{References}

1. Park JW, Chen M, Colombo M, Roberts LR, Schwartz M, Chen PJ, Kudo M, Johnson P, Wagner S, Orsini LS and Sherman M: Global patterns of hepatocellular carcinoma management from diagnosis to death: The bridge study. Liver Int 35: 2155-2166, 2015.

2. Wallace MC, Preen D, Jeffrey GP and Adams LA: The evolving epidemiology of hepatocellular carcinoma: A global perspective. Expert Rev Gastroenterol Hepatol 9: 765-779, 2015.

3. Lei C, Ren D, Fu M, Sun C, Ren H, Pan Q and Li Y: Curative effect of endostar combined with oxaliplatin in the treatment of primary hepatic carcinoma and its influence on immune cells. Oncol Lett 17: 3665-3670, 2019.

4. Trépo C, Chan HL and Lok A: Hepatitis B virus infection. Lancet 384: 2053-2063, 2014.

5. Ichikawa T, Sano K and Morisaka H: Diagnosis of pathologically early HCC with EOB-MRI: Experiences and current consensus. Liver Cancer 3: 97-107, 2014.

6. Hartke J, Johnson M and Ghabril M: The diagnosis and treatment of hepatocellular carcinoma. Semin Diagn Pathol 34: 153-159, 2017.

7. Zhu ZX, Huang JW, Liao MH and Zeng Y: Treatment strategy for hepatocellular carcinoma in China: Radiofrequency ablation versus liver resection. Jpn J Clin Oncol 46: 1075-1080, 2016.

8. Tsurusaki M and Murakami T: Surgical and locoregional therapy of HCC: TACE. Liver Cancer 4: 165-175, 2015.

9. Llovet JM and Bruix J: Systematic review of randomized trials for unresectable hepatocellular carcinoma: Chemoembolization improves survival. Hepatology 37: 429-442, 2003.
10. Raoul JL, Forner A, Bolondi L, Cheung TT, Kloeckner R and de Baere T: Updated use of TACE for hepatocellular carcinoma treatment: How and when to use it based on clinical evidence. Cancer Treat Rev 72: 28-36, 2019.

11. Ito F, Vardam TD, Appenheimer MM, Eng KH, Gollnick SO, Muhitch JB and Evans SS: In situ thermal ablation augments antitumor efficacy of adoptive $\mathrm{T}$ cell therapy. Int J Hyperthermia 36 (Suppl 1): S22-S36, 2019.

12. Löffler MW, Nussbaum B, Jäger G, Jurmeister PS, Budczies J, Pereira PL, Clasen S, Kowalewski DJ, Mühlenbruch L, Königsrainer I, et al: A non-interventional clinical trial assessing immune responses after radiofrequency ablation of liver metastases from colorectal cancer. Front Immunol 10: 2526,2019

13. Zhou J, Sun HC, Wang Z, Cong WM, Wang JH, Zeng MS, Yang JM, Bie P, Liu LX, Wen TF, et al: Guidelines for diagnosis and treatment of primary liver cancer in China (2017 edition). Liver Cancer 7: 235-260, 2018.

14. Zhao S, Wang M, Yang Z, Tan K, Zheng D, Du X and Liu L: Comparison between child-pugh score and albumin-bilirubin grade in the prognosis of patients with $\mathrm{HCC}$ after liver resection using time-dependent ROC. Ann Transl Med 8: 539, 2020.

15. Shimura S, Odagiri S, Furuya H, Okada K, Ozawa K, Nagase H, Yamaguchi $\mathrm{M}$ and Cho Y: Echocardiography-guided aortic cannulation by the Seldinger technique for type A dissection with cerebral malperfusion. J Thorac Cardiovasc Surg 159: 784-793, 2020.

16. Eisenhauer EA, Therasse P, Bogaerts J, Schwartz LH, Sargent D, Ford R, Dancey J, Arbuck S, Gwyther S, Mooney M, et al: New response evaluation criteria in solid tumours: Revised RECIST guideline (version 1.1). Eur J Cancer 45: 228-247, 2009.

17. Shi B, Sun A and Zhang X: Influence of different ex vivo cell culture methods on the proliferation and anti-tumor activity of cytokine-induced killer cells from gastric cancer patients. Onco Targets Ther 11: 2657-2672, 2018.

18. Livak KJ and Schmittgen TD: Analysis of relative gene expression data using real-time quantitative PCR and the 2(-Delta Delta C(T)) method. Methods 25: 402-408, 2001.

19. Gonzalez H, Hagerling $\mathrm{C}$ and Werb Z: Roles of the immune system in cancer: from tumor initiation to metastatic progression. Genes Dev 32: 1267-1284, 2018.

20. Wu X, Peng M, Huang B, Zhang H, Wang H, Huang B, Xue Z, Zhang L, Da Y, Yang D, et al: Immune microenvironment profiles of tumor immune equilibrium and immune escape states of mouse sarcoma. Cancer Lett 340: 124-133, 2013.

21. Quezada SA, Peggs KS, Simpson TR and Allison JP: Shifting the equilibrium in cancer immunoediting: From tumor tolerance to eradication. Immunol Rev 241: 104-118, 2011.

22. Ferrari SM, Fallahi P, Galdiero MR, Ruffilli I, Elia G, Ragusa F, Paparo SR, Patrizio A, Mazzi V, Varricchi G, et al: Immune and Inflammatory Cells in Thyroid Cancer Microenvironment. Int J Mol Sci 20: 2019.

23. Ge P, Wang W, Li L, Zhang G, Gao Z, Tang Z, Dang X and $\mathrm{Wu}$ Y: Profiles of immune cell infiltration and immune-related genes in the tumor microenvironment of colorectal cancer. Biomed Pharmacother 118: 109228, 2019.

24. Wang Y, Zhu C, Song W, Li J, Zhao G and Cao H: PD-L1 expression and CD8(+) $\mathrm{T}$ cell infiltration predict a favorable prognosis in advanced gastric cancer. J Immunol Res 2018: 4180517, 2018

25. Zerbini A, Pilli M, Penna A, Pelosi G, Schianchi C, Molinari A, Schivazappa S, Zibera C, Fagnoni FF, Ferrari C and Missale G: Radiofrequency thermal ablation of hepatocellular carcinoma liver nodules can activate and enhance tumor-specific T-cell responses. Cancer Res 66: 1139-1146, 2006.

26. Darvin P, Toor SM, Nair VS and Elkord E: Immune checkpoint inhibitors: recent progress and potential biomarkers. Exp Mol Med 50: 1-11, 2018.

27. Abril-Rodriguez G and Ribas A: SnapShot: immune checkpoint inhibitors. Cancer Cell 31: 848-848 e841, 2017.

28. Mazieres J, Drilon A, Lusque A, Mhanna L, Cortot AB, Mezquita L, Thai AA, Mascaux C, Couraud S, Veillon R, et al: Immune checkpoint inhibitors for patients with advanced lung cancer and oncogenic driver alterations: Results from the IMMUNOTARGET registry. Ann Oncol 30: 1321-1328, 2019.

29. Wang Z, Zhang C, Liu X, Wang Z, Sun L, Li G, Liang J, $\mathrm{Hu} \mathrm{H}$, Liu Y, Zhang W and Jiang T: Molecular and clinical characterization of PD-L1 expression at transcriptional level via 976 samples of brain glioma. Oncoimmunology 5: e1196310, 2016. 
30. Veloza L, Teixido C, Castrejon N, Climent F, Carrió A Marginet M, Soldini D, González-Farré B, Ribera-Cortada I, Lopez-Guillermo A, et al: Clinicopathological evaluation of the programmed cell death 1 (PD1)/programmed cell death-ligand 1 (PD-L1) axis in post-transplant lymphoproliferative disorders: Association with Epstein-Barr virus, PD-L1 copy number alterations, and outcome. Histopathology 75: 799-812, 2019.

31. Ferrara R, Mezquita L, Texier M, Lahmar J, Audigier-Valette C, Tessonnier L, Mazieres J, Zalcman G, Brosseau S, Le Moulec S, et al: Hyperprogressive disease in patients with advanced non-small cell lung cancer treated with PD-1/PD-L1 inhibitors or with single-agent chemotherapy. JAMA Oncol 4: $1543-1552,2018$

32. Jiang C, Cao S, Li N, Jiang L and Sun T: PD-1 and PD-L1 correlated gene expression profiles and their association with clinical outcomes of breast cancer. Cancer Cell Int 19: 233, 2019.

33. Xie M, Huang X, Ye X and Qian W: Prognostic and clinicopathological significance of PD-1/PD-L1 expression in the tumor microenvironment and neoplastic cells for lymphoma. Int Immunopharmacol 77: 105999, 2019.

34. Hanna GJ, Woo SB, Li YY, Barletta JA, Hammerman PS and Lorch JH: Tumor PD-L1 expression is associated with improved survival and lower recurrence risk in young women with oral cavity squamous cell carcinoma. Int J Oral Maxillofac Surg 47: 568-577, 2018.

35. Dong H, Strome SE, Salomao DR, Tamura H, Hirano F, Flies DB Roche PC, Lu J, Zhu G, Tamada K, et al: Tumor-associated B7-H1 promotes T-cell apoptosis: A potential mechanism of immune evasion. Nat Med 8: 793-800, 2002.

36. Lee JH, Lee JH, Lim YS, Yeon JE, Song TJ, Yu SJ, Gwak GY, Kim KM,Kim YJ,Lee JW and Yoon JH: Adjuvant immunotherapy with autologous cytokine-induced killer cells for hepatocellular carcinoma. Gastroenterology 148: 1383-1391.e6, 2015.

37. Lee JH, Lee JH, Lim YS, Yeon JE, Song TJ, Yu SJ, Gwak GY, Kim KM, Kim YJ, Lee JW and Yoon JH: Sustained efficacy of adjuvant immunotherapy with cytokine-induced killer cells for hepatocellular carcinoma: An extended 5-year follow-up. Cancer Immunol Immunother 68: 23-32, 2018.

38. Liu J,Liu Y, Meng L, Liu K and Ji B: Targeting the PD-L1/DNMT1 axis in acquired resistance to sorafenib in human hepatocellular carcinoma. Oncol Rep 38: 899-907, 2017.

39. Naruse T, Yanamoto S, Okuyama K, Ohmori K, Tsuchihashi H, Furukawa K, Yamada SI and Umeda M: Immunohistochemical study of PD-1/PD-L1 axis expression in oral tongue squamous cell carcinomas: Effect of neoadjuvant chemotherapy on local recurrence. Pathol Oncol Res 26: 735-742, 2020.
40. Walcher L, Kistenmacher AK, Suo H, Dluczek S, Strauß A, Blaudszun AR, Yevsa T, Fricke S and Kossatz-Boehlert U: Cancer stem cells-origins and biomarkers: Perspectives for targeted personalized therapies. Front Immunol 11: 1280, 2020.

41. Oh SJ, Ahn EJ, Kim O, Kim D, Jung TY, Jung S, Lee JH, Kim KK, $\mathrm{Kim} \mathrm{H}, \mathrm{Kim} \mathrm{EH}$, et al: The role played by SLUG, an epithelial-mesenchymal transition factor, in invasion and therapeutic resistance of malignant glioma. Cell Mol Neurobiol 39: 769-782, 2019.

42. Peng J, Hamanishi J, Matsumura N, Abiko K, Murat K, Baba T, Yamaguchi K, Horikawa N, Hosoe Y, Murphy SK, et al: Chemotherapy induces programmed cell death-ligand 1 overexpression via the nuclear factor- $\kappa \mathrm{B}$ to foster an immunosuppressive tumor microenvironment in ovarian cancer. Cancer Res 75: 5034-5045, 2015

43. Baraibar I, Melero I, Ponz-Sarvise M and Castanon E: Safety and tolerability of immune checkpoint inhibitors (PD-1 and PD-L1) in cancer. Drug Saf 42: 281-294, 2019.

44. Chen S, Crabill GA, Pritchard TS, McMiller TL, Wei P, Pardoll DM, Pan F and Topalian SL: Mechanisms regulating PD-L1 expression on tumor and immune cells. J Immunother Cancer 7: 305, 2019.

45. Ma LJ, Feng FL, Dong LQ, Zhang Z, Duan M, Liu LZ, Shi JY, Yang LX, Wang ZC, Zhang S, et al: Clinical significance of PD-1/PD-Ls gene amplification and overexpression in patients with hepatocellular carcinoma. Theranostics 8: 5690-5702, 2018.

46. Kawahara T, Ishiguro Y, Ohtake S, Kato I, Ito Y, Ito H, Makiyama K, Kondo K, Miyoshi Y, Yumura Y, et al: PD-1 and PD-L1 are more highly expressed in high-grade bladder cancer than in low-grade cases: PD-L1 might function as a mediator of stage progression in bladder cancer. BMC Urol 18: 97, 2018.

47. D'Alterio C, Nasti G, Polimeno M, Ottaiano A, Conson M, Circelli L, Botti G, Scognamiglio G, Santagata S, De Divitiis C, et al: CXCR4-CXCL12-CXCR7, TLR2-TLR4, and PD-1/PD-L1 in colorectal cancer liver metastases from neoadjuvant-treated patients. Oncoimmunology 5: e1254313, 2016.

This work is licensed under a Creative Commons Attribution-NonCommercial-NoDerivatives 4.0 International (CC BY-NC-ND 4.0) License. 